\title{
ECOLOGICAL TOURIST POTENTIAL OF SAMARA REGION: FLORA RESOURCES
} (C) 2016

S.V. Saksonov, doctor of biological sciences, professor,

head of Problems of Phytodiversity Laboratory, deputy director for scientific work

A.G. Rozenberg, candidate of biological sciences, junior researcher of Environmental Economics Group

S.A. Senator, candidate of biological sciences, senior researcher of Problems of Phytodiversity Laboratory Institute of Ecology of Volga River Basin of Russian Academy of Sciences, Togliatti (Russia)

I.V. Kazantsev, candidate of biological sciences, dean of Faculty of Natural Sciences and Geography, associate professor of Chemistry, Geography and Methods of Teaching Department

Samara State University of Social Sciences and Education, Samara (Russia)

V.M. Vasjukov, candidate of biological sciences, researcher of Problems of Phytodiversity Laboratory Institute of Ecology of Volga River Basin of Russian Academy of Sciences, Togliatti (Russia)

Abstract. In article development of ecological tourism which, first of all, is based on visit of attractive and unique objects is considered. Flora conforms to these requirements fully.. For the first time 10 bases are formulated which stimulate development of informative ecological tourism (a specific variety, relic types; endemic types; the types described from the territory of the region for the first time for science; the plants recognized protected and included in the Krasnaya kniga; vegetable communities, unique by origin and to structure; zone, typical vegetable communities; places of concentration of plants in the territory of nature sanctuaries; especially valuable natural territories of federal level of protection; key botanical territories) and 5 bases which stimulate development of event ecological tourism (date of birth of researchers; dates of expeditions; dates of the organization of the centers for studying of flora; dates of the publication of the major botanical compositions; dates of the largest scientific forums). Concentration of nature sanctuaries and distribution of especially protected natural territories is described within the Samara Region. In article the generalized criterion for evaluation of the fitosozological status of these territories is used. It is noted that the Samara Region is the perspective territory for development of internal tourism where the important and defining role belongs to ecological tourism.

Keywords: protected areas; nature monuments; ecological tourism; educational tourism; event tourism; species diversity; plant communities; fauna; relics; endemics; rare plants; Red Books; Samara Region.

УДК 504.75.05(470.44)

\section{ОЦЕНКА ВЛИЯНИЯ ИНДЕКСА ЗАГРЯЗНЕНИЯ АТМОСФЕРЫ НА МЕДИКО-ДЕМОГРАФИЧЕСКИЕ ПОКАЗАТЕЛИ ЖИТЕЛЕЙ ГОРОДА САРАТОВА} (C) 2016

\author{
Н.В. Точилкина, старший преподаватель кафедры частного права и экологической безопасности \\ Саратовский соииально-экономический институт \\ Российского экономического университета имени Г.В. Плеханова, Саратов (Россия)
}

\begin{abstract}
Аннотация. В представленной статье рассматривается влияние загрязнения воздуха на демографические характеристики жителей г. Саратова. Описываются основные загрязнители воздуха, оказывающие значительное влияние на заболеваемость неинфекционными заболеваниями, а также на уровень детской смертности. Рассматривается влияние как комплексного показателя уровня загрязнения атмосферы, так и его компонентов на общий уровень смертности, уровень смертности от онкологических заболеваний, от заболеваний органов дыхания и уровень смертности детей до 1 года. Проведенные исследования показали, что существует тесная прямая связь между комплексным показателем загрязнения воздуха и смертностью от заболеваний органов дыхания, а также уровнем детской смертности. Также выявлено, что уровень общей смертности тесно связан с превышением содержания в воздухе оксида азота, уровень смертности от онкологических заболеваний - с превышением содержания оксида азота и фенола, уровень смертности от заболеваний органов дыхания - с превышением содержания формальдегида, уровень смертности детей в возрасте до одного года - с превышением содержания формальдегида и фенола. Несмотря на важность и актуальность подобных исследований, отмечается сложность в доступе к сведениям о заболеваемости по классам заболеваний, по полу и возрасту жителей различных административных районов города. Это не позволяет проводить в полном объеме анализ текущей ситуации и ретроспективные исследования для ее прогнозирования.

Ключевые слова: загрязнение воздуха; комплексный показатель уровня загрязнения атмосферы; уровень общей смертности; уровень смертности от заболеваний органов дыхания; уровень смертности от онкологических заболеваний; уровень смертности детей в возрасте до одного года; г. Саратов.
\end{abstract}

Ежегодно количество горожан увеличивается почти на 70 млн. человек, и весь комплекс городских проблем, связанных как социально-экономической адаптацией населения, так и с оптимизацией его плотности, является одной из характеристик урбоэкосистемы. Экологические проблемы городской жизни многогранны и разноплановы, они могут определяться множеством факторов, однако только удобство и качество жизни горожанина будут интегральной оценкой их решения, правильность которого - высокая продолжительность жизни и низкий уровень заболеваемости. 
Важнейшей составляющей качества городской жизни является чистота окружающей среды, и в первую очередь воздуха. Несмотря на то, что ВОЗ определила среднее значение удельного веса влияния факторов окружающей среды на состояние здоровья населения 17-20\%, по данным той же организации, в 2012 году погибло около 7 миллионов человек - один в восьми из общего числа случаев смерти в мире - в результате воздействия загрязнения воздуха. Это более чем в два раза превышает предыдущие оценки и подтверждает, что загрязнение воздуха является одним из наиболее опасных видов воздействия окружающей среды на здоровье человека [1].

По мнению Европейского агентства по окружающей среде (ЕАОС) [2], загрязнение воздуха в городах может стать главной экологической причиной смертности во всем мире к 2050 году, достигнув 3,6 млрд. человек, в основном за счет стран БРИКС [3]. Однако и для европейских стран загрязнение воздуха остается важной причиной заболеваемости неинфекционными заболеваниями (НИЗ), такими как хронические респираторные заболевания, рак легких, сердечно-сосудистые заболевания. Накапливаются свидетельства и других вредных последствий загрязнения воздуха для здоровья, включая замедление роста плода и преждевременные роды при воздействии загрязнения в дородовой период, а также последствия для здоровья во взрослом возрасте при воздействии в перинатальный период [4].

За последние десятилетия ВОЗ накопила определенную статистику, наглядно демонстрирующую тесную связь между характеристиками воздушной среды и состоянием здоровья, которое может быть выражено как количеством смертей, так и показателем DALY (Disability-adjusted life year), оценивающим суммарное «бремя болезни». Такая работа позволяет каждому государству определить наиболее важные и неотложные направления по защите своей атмосферы и достижению показателей приемлемой чистоты воздуха. Обеспечение условий такой работы - одна из задач городской власти, решение которой представляет собой совокупность мероприятий технологического и административного характера. Для управленцев, которые должны обеспечивать защиту воздушного бассейна, важно не только получать информацию в оперативном режиме и правильно ее интерпретировать, но и выстраивать превентивную систему защиты. Мероприятия, направленные на предупреждение загрязнения, позволят в конечном итоге сохранить жизнь и здоровье людей, что экономически более оправдано, чем лечение или потеря трудоспособности. Однако для такой территориально и демографически неоднородной страны, как Россия, огромное значение имеет региональный аспект проблемы, учитывающий как климатические особенности, так и экономическую направленность развития территории. В связи с этим целью работы является оценка влияния комплексного показателя загрязнения атмосферы ИЗА 5 и его составляющих на ряд медико-демографических характеристик жителей г. Саратова.

Несмотря на целый ряд трудностей, возникающих при изучении влияния загрязнения воздуха на здоровье и благополучие человека: комплексный характер поллютантов, их различное суммарное воздействие и отложенный во времени ущерб здоровью, - накопившиеся данные позволяют говорить о множественном характере этого воздействия (рис. 1). Так, в отчете EEA [4] приведены ссылки на ряд исследований, устанавливающих сильную взаимосвязь между кратковременным воздействием твердых частиц и инфарктом миокарда, загрязнением воздуха и увеличением заболеваемости ишемическим инсультом.

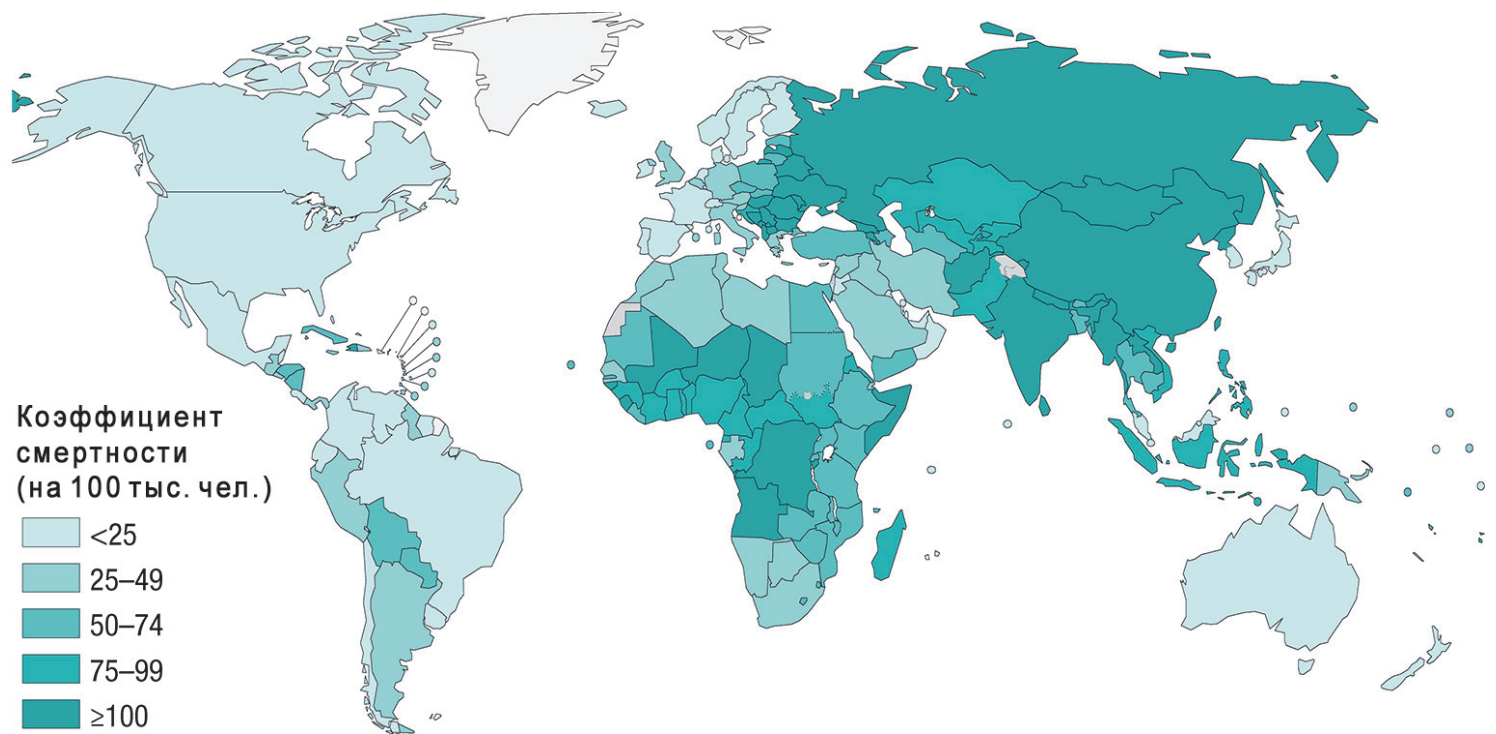

Рисунок 1 - Уровень смертности, обусловленный загрязнением атмосферного воздуха, по регионам ВОЗ, 2012 [5]

В России система мониторинга предусматривает измерение концентрации взвешенных веществ (TSP), однако исследования, проведенные Э.Ю. Безуглой, И.В. Смирновой показали практически равноценную информативность этих показателей с точки зрения представления о загрязненности воздуха [6].

Важно также отметить, что некоторые группы населения являются более уязвимыми при воздей- ствии загрязненного воздуха в силу своего возраста, состояния здоровья, а также социальных, культурных и экономических условий. Восприимчивость определяется не только личными характеристиками, но также, например, моделями временной активности, характеристиками жилья и условиями окружающей среды в районе проживания. Например, смерть происходит чаще среди тех, кто уже болен, - людей с суще- 
ствующими заболеваниями сердца, органов дыхания или с наличием других хронических заболеваний.

Наиболее подверженными воздействию воздушного загрязнения являются дети, так как они проводят много времени на открытом воздухе, имеют более высокую частоту дыхания, а также дышат большим объ- емом воздуха относительно веса тела. Маленькие дети и младенцы могут быть особенно чувствительны к воздействию загрязнения воздуха, потому что их иммунная, дыхательная и центральная нервная системы еще не в полной мере сформированы (BO3, 2005) (рис. 2).

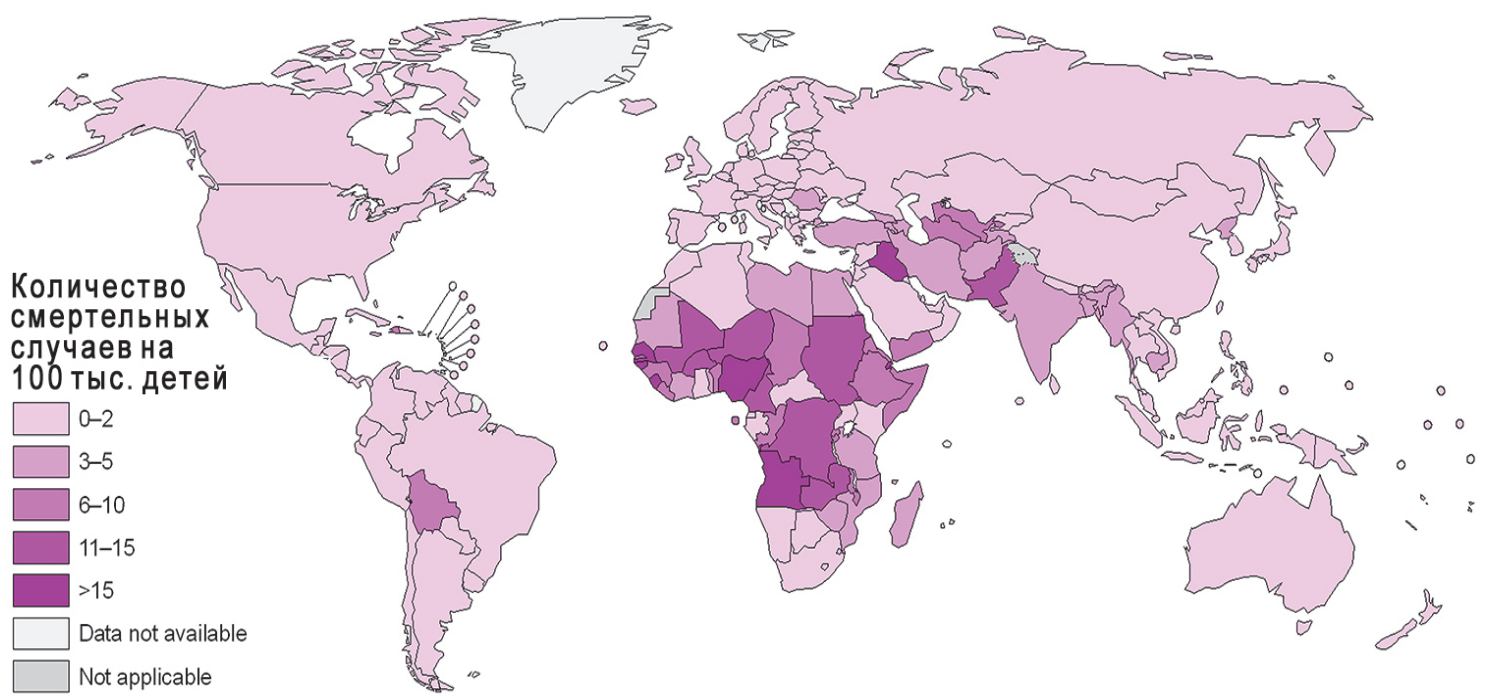

Рисунок 2 - Число смертельных случаев, связанных с загрязнением атмосферного воздуха, у детей в возрасте до 5 лет, на 100000 детей [7]

В России качество атмосферного воздуха согласно РД 52.04.667-2005 [8] имеет 4 степени загрязнения: низкую «Н», повышенную «П», высокую «В» и очень высокую «ОВ». Росгидромет ежегодно публикует результаты наблюдений за состоянием воздушного бассейна в регионах и городах страны. По данным Ежегодника за 2014 год, г. Саратов с 2010 по 2014 года имел категорию загрязнения «В», а в 2013 даже «ОВ» [9]. Тем не менее г. Саратов с 2013 года не входит в Приоритетный список городов России с наибольшим уровнем загрязнения воздуха. Связано это преимущественно с изменением ПДК с.с. формальдегида [10], что иллюстрируют данные, приведенные Росгидрометом (рис. 3).

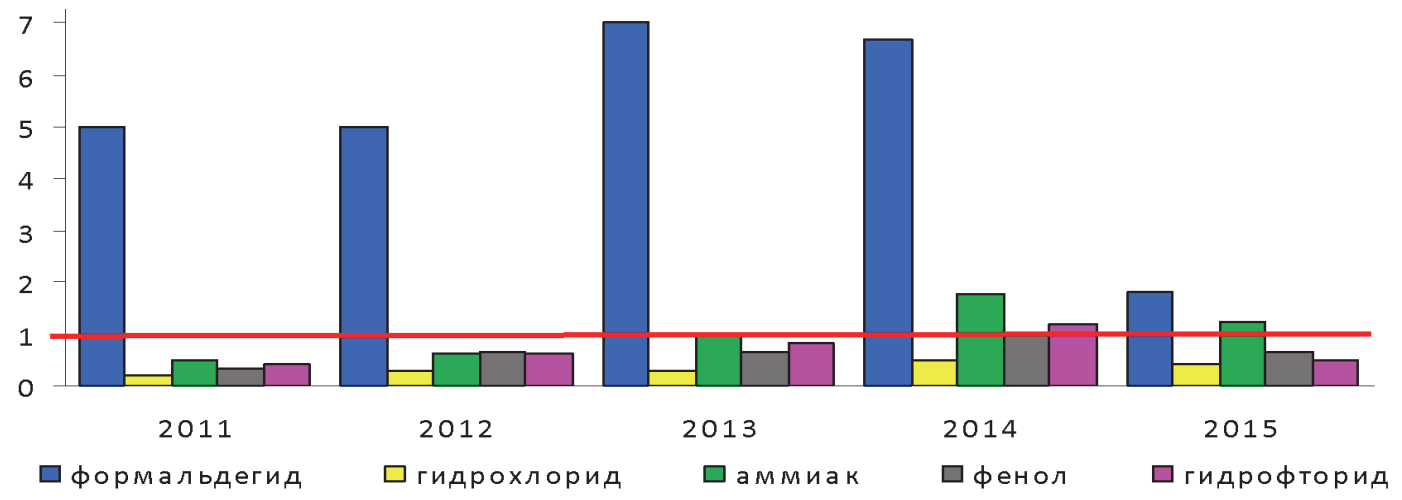

Рисунок 3 - Динамика уровня загрязнения атмосферного воздуха г. Саратова (доли ПДК с.с.) [12]

Учитывая, что влияние качества воздуха на здоровье человека имеет пролонгированный характер, имеет смысл оценить тот его показатель, который в первую очередь учитывается при оценке годовой степени загрязненности - индекс загрязнения атмосферы ИЗА. Расчеты показали, что наибольший вклад в загрязнение воздуха города вносят формальдегид, диоксид азота, пыль, оксид углерода и фенол, при этом в расчетах мы использовали неизмененный ПДК с.с. формальдегида за 2014 год. Для Саратова, где наибольший вклад в загрязнение воздуха вносит именно формальдегид, методы расчета имеют большое значение, так как занижение показателей лишь маскирует проблему, не устраняя ее (рис. 4). Согласно новой методике расчета ИЗА формальдегида упал в 5 раз, а комплексный показатель ИЗА 5 снизился почти в 3 раза. При этом, согласно данным Росгидромета [11], за период с 2010 по 2014 гг. концентрация в атмосфеpe формальдегида увеличилась. Ежегодный отчет Росгидромета [12] приводит данные о приоритете формальдегида в перечне основных загрязнителей атмосферы многих городов России, однако Саратов назван в числе городов с максимальным превышением содержания этого веществ даже с учетом изменения ПДК с.с.

В этой связи представляется важным обратить внимание на повышенное содержание в атмосфере города формальдегида, который относится ко 2 классу опасности и обладает высокой токсичностью. Высокая концентрация этого вещества угнетающе действует на центральную нервную систему, могут поражаться слизистые оболочки глаз и верхних дыхательных путей. Наиболее существенное влияние его повышенное содержание может оказать на здоровье детей [13]. 


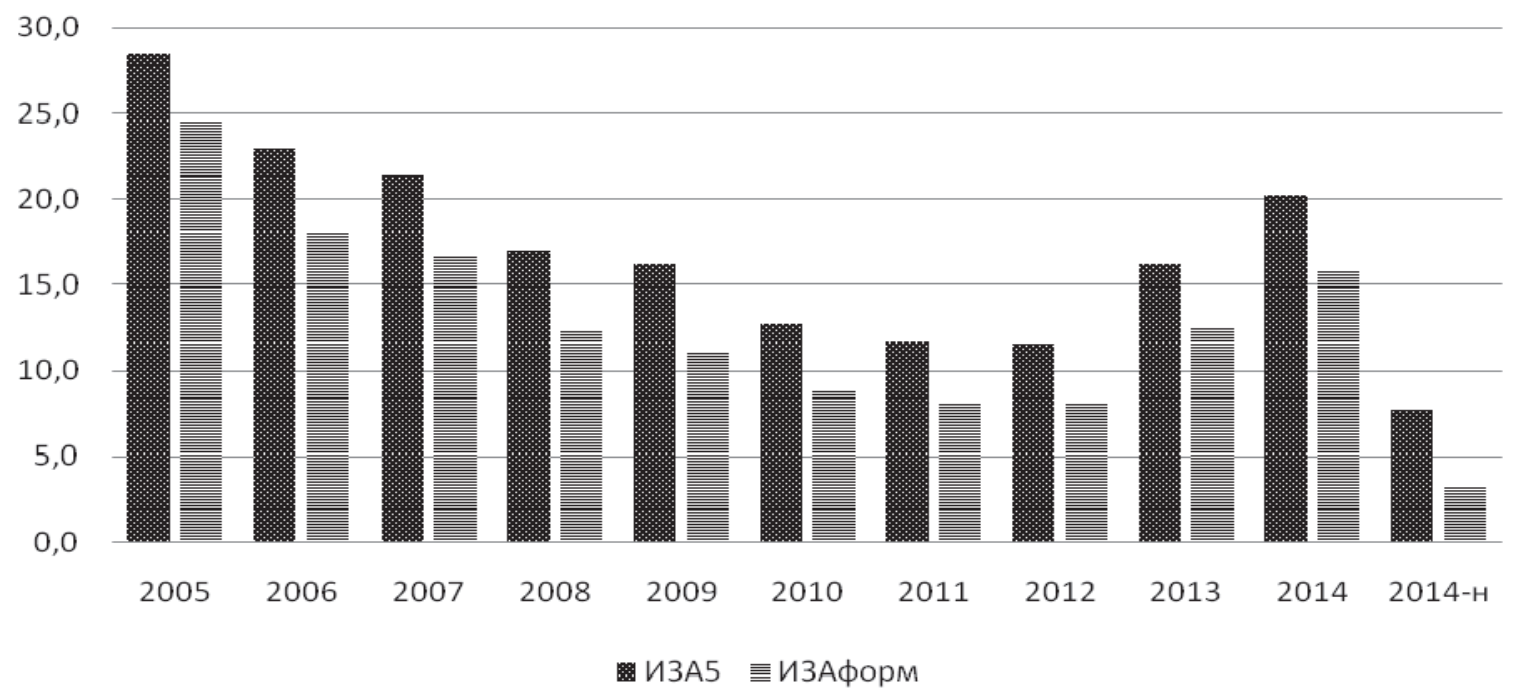

Рисунок 4 - Динамика изменения комплексного ИЗА г. Саратова и ИЗА формальдегида (данные по 2014 год приведены в старой и новой редакции документа)

Еще один воздушный загрязнитель, значительно ухудшающий работу в первую очередь дыхательной системы человека, - оксид азота. Его уровень воздействия на здоровье может носить как кратковременный характер (например, изменения в функции легких у чувствительных групп населения), так и иметь долгосрочную перспективу (например, повышение восприимчивости к респираторным инфекционным заболеваниям). Эпидемиологические исследования показали, что симптомы бронхита у детей с бронхиальной астмой могут увеличиться в связи с долгосрочным воздействием $\mathrm{NO}_{2}$ [14].

Длительное загрязнение воздуха влечет за собой изменения в показателях здоровья горожан, что проявляется в новых закономерностях распространения патологий человека и изменении протекания демографических процессов $[15 ; 16 ; 17]$. Наибольший ин- терес в этом аспекте представляет собой анализ динамики структуры уровня смертности по основным классам причин смерти и его возрастная специфика. В нашем исследовании мы рассмотрели влияние комплексного показателя загрязнения воздуха ИЗА5 и его компонентов на общий уровень смертности, уровень смертности от онкологических заболеваний, от заболеваний органов дыхания и уровень смертности детей до 1 года для жителей г. Саратова.

На графиках представлена динамика изменения ИЗА $_{5}$ и уровня смертности от заболеваний органов дыхания (рис. 5), а также ИЗА 5 и уровня смертности детей до 1 года (рис. 6). Расчет коэффициентов корреляции показал тесную прямую связь для обоих показателей: 0,66 для ИЗА 5 и смертности от заболеваний органов дыхания и 0,87 для ИЗА 5 и уровня детской смертности.

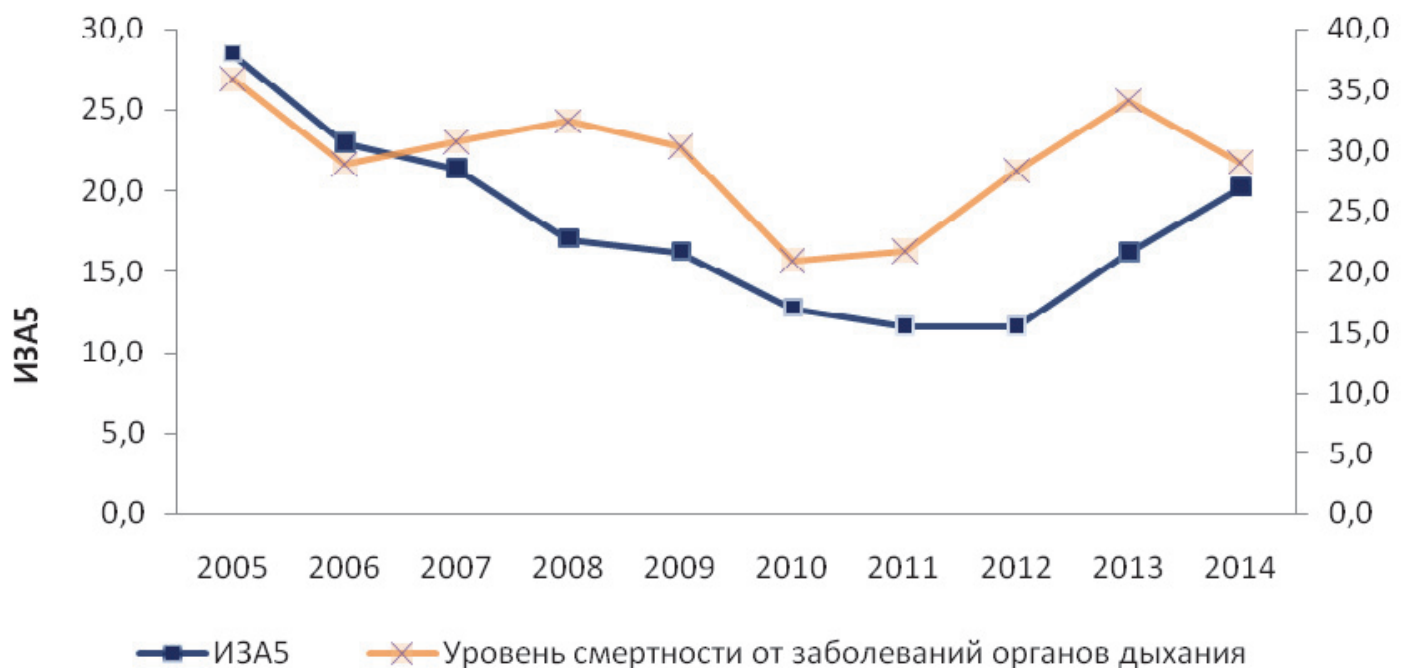

Рисунок 5 - Динамика изменения ИЗА 5 и уровня смертности от заболеваний органов дыхания, г. Саратов, 2005-2014 гг.

Затем был проведен корреляционный анализ для каждой компоненты ИЗА 5 и исследуемых демографических параметров. Наши исследования показали, что с вероятностью 95\% уровень общей смертности тесно связан с превышением содержания в воздухе оксида азота $(\mathrm{r}=0,74)$, уровень смертности от онкологических заболеваний - с превышением содержа- ния оксида азота и фенола ( $\mathrm{r}=0,68$ и $\mathrm{r}=0,78$ соответственно), уровень смертности от заболеваний органов дыхания - с превышением содержания формальдегида (ПДК с.с. $\left.0,003 \mathrm{Mr} / \mathrm{M}^{3}\right) \quad(\mathrm{r}=0,66)$, уровень смертности детей в возрасте до одного года - с превышением содержания формальдегида ${ }^{1}$ и фенола ( $\mathrm{r}=0,89$ и $\mathrm{r}=74$ соответственно). 


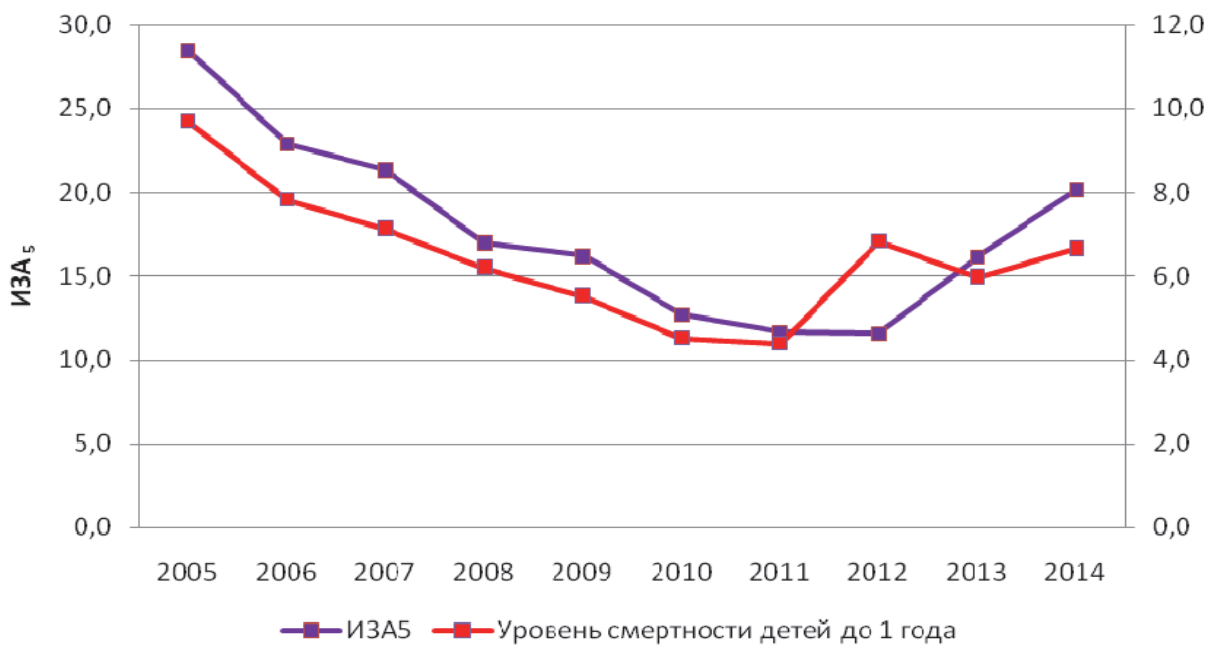

Рисунок 6 - Динамика изменения ИЗА 5 и уровня смертности детей до 1 года, г. Саратов, 2005-2014 гг.

Повышенное содержание формальдегида в атмосфере города имеет, очевидно, антропогенный характер, так как, по мнению С.В. Какареки и Ю.Г. Ашурко [18], основной вклад в выбросы формальдегида вносят передвижные источники. По данным Министерства природных ресурсов и экологии Саратовской области, вклад передвижных источников в суммарный выброс загрязняющих веществ составляет около $70 \%$ [19]. Однако Э.Ю. Безуглая и др. [20] считают, что повышенное содержание формальдегида связано не с возросшей транспортной нагрузкой, о чем в первую очередь свидетельствует высокое содержание оксидов азота, а с процессами, активно протекающими в атмосфере. Тропосферное происхождение формальдегида подтверждается и исследованиями А.Ф. Ануфриевой, И.В. Смирновой [21], по данным которых, повышение температуры воздуха в среднем на $3,6^{\circ} \mathrm{C}$ обеспечило рост концентрации формальдегида в городах в 2-6 раз. Высокая инсоляция в летнее время, слабый ветер и отсутствие осадков способствуют образованию фотохимического смога, одним из продуктов которого является формальдегид. Учитывая, что Саратов расположен в зоне повышенного потенциала загрязнения атмосферы, а климатические условия неблагоприятны для рассеивания примесей, при неизменной ситуации с загрязнением атмосферы города можно предположить дальнейший рост заболеваемости и смертности как от онкологических заболеваний, так и от заболеваний органов дыхания.

Безусловно, можно отметить, что не всегда превышение ПДК с.с. загрязняющих веществ, доступных для изучения в российских статистических отчетах, тесно связано с изменением популяционных характеристик населения конкретной территории. Однако, несмотря на то, что современные экологические исследования во всем мире показывают, что именно медико-демографические показатели населения являются наиболее чувствительными к загрязнению окружающей среды, в российской статистике попрежнему очень сложно найти их по конкретным населенным пунктам. Недоступность сведений о заболеваемости по классам заболеваний, по полу и возрасту жителей различных административных районов города не позволяет проводить в полном объеме анализ текущей ситуации и ретроспективные исследования для ее прогнозирования. Тем не менее даже те сведения, которые есть в открытом доступе, свидетельствуют о тесной связи загрязнения воздуха оксидами азота, формальдегидом и фенолом и повышением уровня смертности, в первую очередь детей первого года жизни и людей с онкологическими заболеваниями и заболеваниями органов дыхания. Очевидно, что повышение качества жизни горожан в этой связи должно включать в себя не только планирование и проведение защитных мероприятий технического, технологического и организационного характера, но и информационную доступность сведений относительно общественного здоровья, не являющихся государственной тайной.

\section{СПИСОК ЛИТЕРАТУРЫ:}

1. Бремя болезней от загрязнения окружающей среды и домашнего воздуха [Электронный ресурс] // http://who.int/phe/health_topics/outdoorair/databases/en.

2. Окружающая среда Европы: состояние и перспективы 2015. Обобщающий доклад. [Электронный pecypc] // http://eea.europa.eu/soer-2015/global/health.

3._Организация Объединенных Наций. Цели развития тысячелетия: доклад за 2013 год [Электронный pecypc] // http://unstats.un.org/unsd/mdg/resources/static/ products/progress2013/russian2013.pdf.

4. Environment and human health // EEA Report No 5/2013 [Электронный pecypc] // http://eea.europa.eu/ publications/environment-and-human-health.

5. World Health Organization [Электронный pecypc] // http://gamapserver.who.int/maplibrary/files/maps/global _airpollution_mortality_2012.png.

6. Безуглая Э.Ю., Смирнова И.В. Воздух городов и его изменения. СПб.: Астерион, 2008. 254 с.

7. World Health Organization [Электронный pecypc] // http://gamapserver.who.int/mapLibrary/Files/Maps/Global iap_death_under5_2004.png.

8.РД 52.04.18 $\overline{6}-89$ Руководство по контролю загрязнения атмосферы [Электронный ресурс] // http://gostrf.com/normadata/1/4293791/4293791180.pdf.

9. Ежегодник «Состояние загрязнения атмосферы в городах на территории России за 2014 г.» [Электронный ресурс] // http://voeikovmgo.ru/ru/deyatelnost/ publikacii.

10. Постановление Главного государственного санитарного врача РФ от 17 июня 2014 г. № 37 «О внесении изменения № 11 в ГН 2.1.6.1338-03 «Предельно 
допустимые концентрации (ПДК) загрязняющих веществ в атмосферном воздухе населенных мест» [Электронный pecypc] // http:/garant.ru/products/ipo/ prime/doc/70592956.

11. Обзор состояния и загрязнения окружающей среды на территории деятельности Саратовского ЦГМС - филиала ФГБУ «Приволжское УГМС» за 2015 г. [Электронный pecypc] // http://pogoda-sv.ru/ docs/ecology_info/ecology_review/sar_2015.pdf.

12. Ежегодник Состояние загрязнения атмосферы в городах на территории России за 2014 г. ФГБУ «Главная геофизическая обсерватория им. А.И. Воейкова», Росгидромет. СПб, 2015 г. 288 с.

13. Сысоева Т.И., Карпова Л.С., Безуглая Э.Ю Оценка влияния загрязнения атмосферного воздуха формальдегидом на суммарную заболеваемость гриппом и ОРВИ в 29 городах России // Ежемесячный научно-практический бюллетень «Здоровье населения и среда обитания». № 3 (264), март 2015. С. 45-48.

14. World Health Organization. Air Quality Guidelines global update 2005. Report on working group meeting [Электронный pecypc] // http://euro.who.int/_data/ assets/pdf_file/0008/147851/E87950.pdf.

15. Амреева К.Е., Омирбаева С.М. Оценка риска влияния техногенного загрязнения атмосферного воздуха на здоровье населения в условиях центрального Казахстана [Электронный ресурс] // Современные проблемы науки и образования. 2012. № 6. http://www.science-education.ru/ru/article/view?id=7452.

16. Хотько Н.И., Дмитриев А.П. Санитарное состояние атмосферного воздуха и здоровье населения // Известия высших учебных заведений. Поволжский регион. Медицинские науки. № 2 (22). 2012. С. 125-134.

17. Молодцева А.В. Экологическая оценка воздействия загрязнения атмосферного воздуха на здоровье населения (на примере Ивановской области): автореф. дис. ... канд. биол. наук. Владимир, 2013. 24 с.

18. Какарека С.В., Ашурко Ю.Г. Анализ и оценка источников выбросов формальдегида в атмосферный воздух на территории Беларуси // Природопользование. Вып. 21., 2012. С. 75-82.

19. Доклад «О состоянии и об охране окружающей среды Саратовской области в 2013 году». Саратов, 2014. 244 c.

20. Безуглая Э.Ю., Воробьева И.А., Полуэктова М.В. Исследование химических процессов в атмосфере по данным мониторинга в городах // Труды главной геофизической обсерватории им. А.И. Воейкова, № 561. 2010. С. 164-184.

21. Ануфриева А.Ф., Смирнова И.В. Влияние аномальных погодных условий на формирование уровня загрязнения атмосферного воздуха в городах России // Труды главной геофизической обсерватории им. А.И. Воейкова. № $566 . \quad$ 2012. С. 246-256.

\section{ESTIMATION OF AIR POLLUTION INFLUENCE ON DEMOGRAPHIC AND HEALTH OF THE POPULATION OF SARATOV}

(C) 2016

N.V. Tochilkina, senior lecturer of Private Law and Environmental Security Department Saratov Institute of Social Sciences and Economics of Plekhanov Russian University of Economics, Saratov (Russia)

Abstract. The article examines the impact of air pollution on the demographic characteristics of the residents of Saratov. It describes the main air pollutants that have a significant impact on the incidence of non-communicable diseases and child mortality. The author discusses the impact of complex index of air pollution and its components on overall mortality rates, mortality from cancer, respiratory diseases and the mortality rate of children under one year. The research has shown that there is a strong direct relationship between the complex index of air pollution and mortality from respiratory diseases and infant mortality rates. The author also reveals that the total mortality rate is closely associated with the increased content in the air of nitrogen oxide, the mortality rate from cancer with the increased content of nitrogen oxide and phenol, the mortality rate from respiratory diseases with excess of formaldehyde, the mortality rate of children under one year - with excess of formaldehyde and phenol. Despite the importance and relevance of such studies the author notes that it is difficult to access the information about morbidity by classes of diseases, by age and sex of the inhabitants of various administrative areas of the city. It does not enable a full analysis of the current situation and retrospective studies for its prediction.

Keywords: air pollution; comprehensive indicator of air pollution level; overall mortality level; mortality from respiratory diseases; mortality rate from cancer; infant mortality; Saratov.

УДК 552.12

\section{ЭКОЛОГО-ТАКСОНОМИЧЕСКИЙ АНАЛИЗ ПЕТРОФИЛЬНОЙ ФЛОРЫ ОКРЕСТНОСТЕЙ СЕЛА ИХРЕК РУТУЛЬСКОГО РАЙОНА РЕСПУБЛИКИ ДАГЕСТАН} (C) 2016

А.М. Халидов, кандидат биологических наук, доцент кафедры ботаники Дагестанский государственный университет, Махачкала (Россия)

Аннотация. Изучение петрофитов как своеобразной группы растений, приуроченной к каменистым субстратам, важно для познания истории флоры и природы в целом. Их экологические особенности, таксономический состав, географо-генетические связи и другие характеристики несут в себе информацию об этапах становления горной страны и ее флоры. Рутульский район входит в состав Высокогорного сланцевого Дагестана и граничит на юге с Республикой Азербайджан, на востоке с Ахтынским и Курахским районами, на северозападе с Тляратинским и Чародинским районами, на севере с Кулинским, Агульским и Лакским районами Рес- 